\title{
Foldable Front Child-Seat Design for Scooter Motorcycle: Strength Analysis Under Static and Dynamic Loading
}

\author{
Siti Zulaikah, Wahyu Haykal Rahmanda, Farid Triawan* \\ Department of Mechanical Engineering, Faculty of Engineering and Technology, Sampoerna University, Indonesia \\ *Email: farid.triawan@sampoernauniversity.ac.id
}

\begin{abstract}
Nowadays, motorcycle is considered as one of the most practical transportation mode in Indonesia. It has become a common practice that a motorcycle rider often brings a small child using a child seat while riding. However, the used child seat is usually not safe and can easily fall off from the motorcycle due to the lack of safety consideration. Moreover, it is very risky to ride a motorcycle with a small child, knowing that motorcycles are the highest contributor to road traffic accidents. For this reason, this paper proposes a primary design idea of a foldable child safety-seat that can be placed on the front part of a scooter motorcycle. This design is also completed with strength analysis to evaluate the components' safety for children under five years old with a weight of around $50 \mathrm{~kg}$. The strength calculation of the frame is done by a theoretical approach under static and dynamic loading. According to the analysis, the proposed child seat design could provide a factor of safety of more than 3.6 for static loading and 1.6 for dynamic loading. This study is expected to be used as a reference for developing a more reliable child safetyseat for motorcycle rider in Indonesia.
\end{abstract}

\section{Keywords}

Children; Foldable child-seat; Scooter motorcycle; Safety; Static and dynamic loading; Frame

\section{Introduction}

In Indonesia, motorcycle is the most popular transportation mode because of its faster traveling time [1]. Many Indonesian people ride motorcycle together with their family. However, this condition is not safe, especially for the child pillion riders, as they usually do not use a proper child safety-seat. Based on the previous researches $[2,3]$, it is found that motorcycle is mostly involved in a road traffic accident which makes motorcycles become the cause of injury with the highest percentage. Moreover, it also can give trauma to the children and a high risk of fatality. According to macro data analysis of traffic accidents in Indonesia from 2004 to 2014 [4], the average fatality rate per 10,000 automobiles, excluding motorcycles, is 13 . However, the average fatality rate per 10,000 automobiles drops to 2.5 with motorcycle included in the calculation. This data clearly shows that motorcycle contributes significantly to road traffic accidents.

Therefore, a lot of innovation of child-seat products for a motorcycle is made to give extra space and a comfortable seat for the children. Besides, this can also help the rider to be more focus on the road [5]. One child-seat made from rattan or bamboo is made to fit in the front deck of a scooter or duck motorcycle. However, the safety of using a rattan or bamboo seat is low since it can disrupt the balance of the rider [6]. Other child seat products made by steel material can also be found easily in the market. The manufactures try to make it efficient to be brought and used.

However, the safety level of those child-seats could not be further confirmed, especially for Indonesian people. The possibility of the child getting injured when an accident occurs is not much different when the child is standing on the front deck or sitting on the middle deck of the motorcycle. Because of that, the World Health Organization (WHO) recommends several ways to prevent fatal accidents for children while on the road. One of them is providing some protective equipment in the vehicle for children such as a strong and curb childseat system and is equipped with a seatbelt [7]. It is highly recommended to use appropriate safety equipment such as seat belt, although it is not a legal requirement to minimize an injury [2]. 
Referring to the typical condition of a motorcycle rider in Indonesia; the child-seat is usually located either in the front side or rear side of the motorcycle. These two locations can affect the condition of the rider and the children. Putting the child in the front side can help the rider to have more control in order to guard their child while riding the motorcycle compared to when the child is sat in the rear side. However, based on the policy, as stated in Undang-Undang No. 22 of 2009, the rider can only bring one passenger. Therefore, they cannot bring more than one passenger. Furthermore, based on the policy of Peraturan Pemerintah No. 74 of 2014, it is stated that the maximum load that can be held by a scooter motorcycle is around $120-125 \mathrm{~kg}$.

The main objective of this paper is to create a safety child-seat motorcycle for children in Indonesia. The seat is addressed for children under five years old with a maximum weight of $50 \mathrm{~kg}$. This number is an approximation for the calculation and analysis purpose. The weight of 5-year-old child is usually around 25-35 $\mathrm{kg}$ [8] and the weight of the chair is around $5 \mathrm{~kg}$. Therefore, the assumed weight of $50 \mathrm{~kg}$ is considered big enough. The design is created by using qualitative data analysis from references, journals, and other sources on the internet. All components are analyzed theoretically under static and dynamic loading. Furthermore, life prediction to know whether the design has an infinite life or not under the dynamics loading is also provided by fatigue analysis. The child-seat is made to be foldable and adjustable to save space when it is not used. This design is expected to be marketable in Indonesian society to be used as the additional seat for their children when traveling by motorcycle.

\section{Methodology}

\subsection{Design concept}

Firstly, the child-seat was designed to stand with one buffer to support the whole weight. However, this idea was realized not strong enough to hold the whole seat in a stable position, hence the child-seat with two buffers (supports) is decided to be the design specification. Although the two buffers can add more weight of the child seat, it was adopted because it can give stronger support for the whole chair and the child load. In other words, the design put the child safety as the top priority.

The seat is also designed to have foldable feature. To obtain this function, the seat consists of a slider, hinge, and other components which make it easier to be adjusted and folded. Figure 1 shows the proposed foldable child-seat design in the installed and folded condition.
The dimensions of the chair are determined by following the dimension of the motorcycle. The width has been ascertained to not exceed the width of the steering handlebar of the motorcycle following the driving rule in Indonesia [9]. Specifically, the data was taken from the dimension of Honda Vario motorcycle [10]. The type of the motorcycle is an automatic scooter motorcycle. Compared with other scooters, Honda Vario motorcycle is larger in size which causes the dimension and space of the child-seat to be bigger. The big size makes the child-seat to be heavier resulting in a more stable child-seat.

\subsection{Material selection}

The material for the child-seat frame should be strong but not heavy. The weight should be light enough therefore it can be moved easily and fulfill the maximum weight requirement of the driving rule in Indonesia [9]. Based on this condition, steel material is a suitable option. Steel material has many advantages which are: i) it has high strength-per-unit mass, ii) it can be easily fabricated and produced massively, iii) has a flexible structure, iv) cheap, v) durable, and vi) it can be reused and recycled resulting in a less environmental impact $[11,12]$. Therefore, this proposed design used steel material for the frame. The dimension is optimized to be small enough to achieve a light weight. It is selected after some trials and errors until the design can get the desired safety factor.

The material that is used for the frame of this child-seat is Cold-Drawn Steel AISI 1020 [13]. This material has some characteristics such as low hardenability properties, low tensile carbon steel with a Brinell hardness of 119-235, high machinability, high strength, high ductility, and good weldability. This high machinability and good weldability are obtained due to the cold drawn or turned polished condition. Therefore, it can make the process of making or manufacturing (drilling, turning, milling, tapping, and welding) of the child-seat easier as this process will be the most applied to this design. Then, referring to Shigley's book [14], the yield and ultimate strength of the material are 390 $\mathrm{MPa}$ and $470 \mathrm{MPa}$, respectively. The material also assumed to have $30^{\circ} \mathrm{C}$ of working temperature. This temperature is obtained from the approximation of the maximum temperature that occurred in Indonesia [15]. 


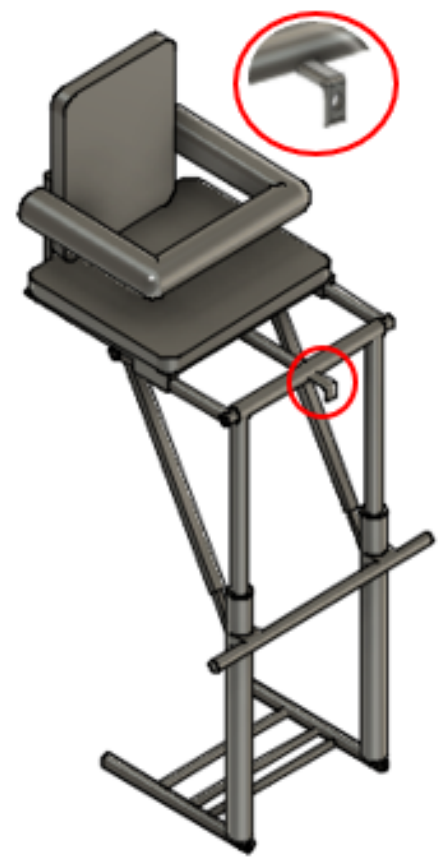

(a)

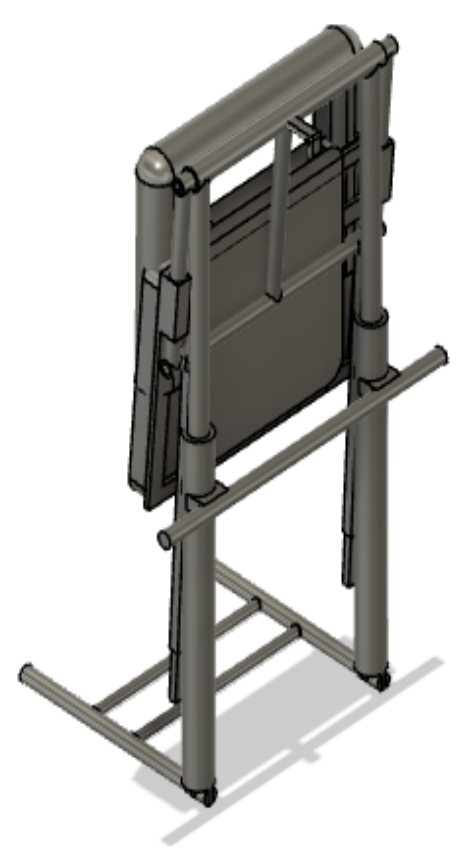

(b)

Figure 1 Isometric view of proposed foldable childseat design with (a) installed condition and (b) folded condition. The red circle shows part of the child-seat that will be attached to the front of the scooter motorcycle by a bolt.

\subsection{Seat's components}

There are two types of shapes that are used to make the whole frame component of this design, which are rectangular and cylindrical (tube). Figure 2 shows two joined components (indicated by two different colors) that are used as the plate frame to sustain the seat's cushion. These two components are joined by welding and hinge so that it can be folded. Then, two sliders are attached to the tube to make the frame possible to slide (or adjustable). Furthermore, Figure 3 shows a tubes frame with six components. Here, the light green color indicates a rectangular tube as the support component which will be attached to the components 1 and 4 which are the buffer that supports the whole chair. Component 5 and 6 are the support that keep the chair steady and fixed in the middle. Moreover, the numbered component is a hollow tube in which the diameter and its thickness is listed in Table 1.

Table 1 The diameter of the hollow tube.

\begin{tabular}{ccc}
\hline No & Outer Diameter (cm) & Thickness (cm) \\
\hline 1 & 1.5 & 0.5 \\
2 & 2.0 & 0.5 \\
3 & 1.5 & 0.5 \\
4 & 3.0 & 1.0 \\
5 & 1.5 & 0.5 \\
6 & 1.0 & 0.5 \\
\hline
\end{tabular}

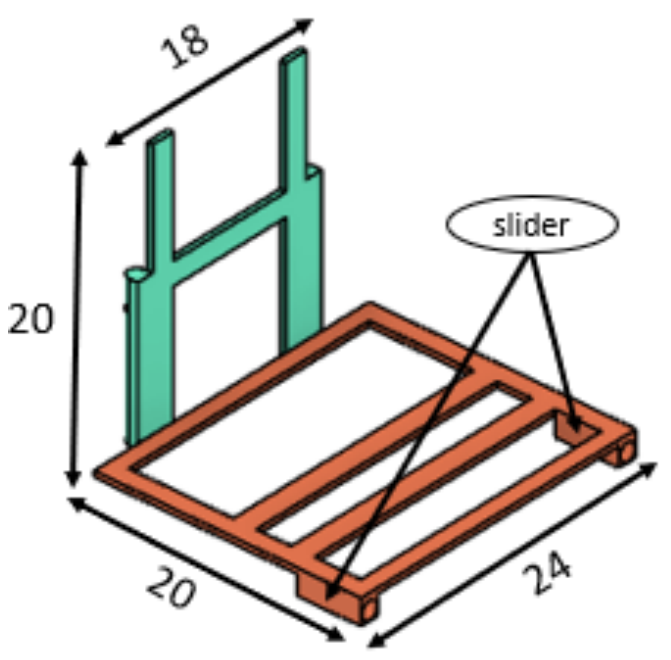

Figure 2 Plate frame for the cushion base (all dimensions in $\mathrm{cm}$ ). 


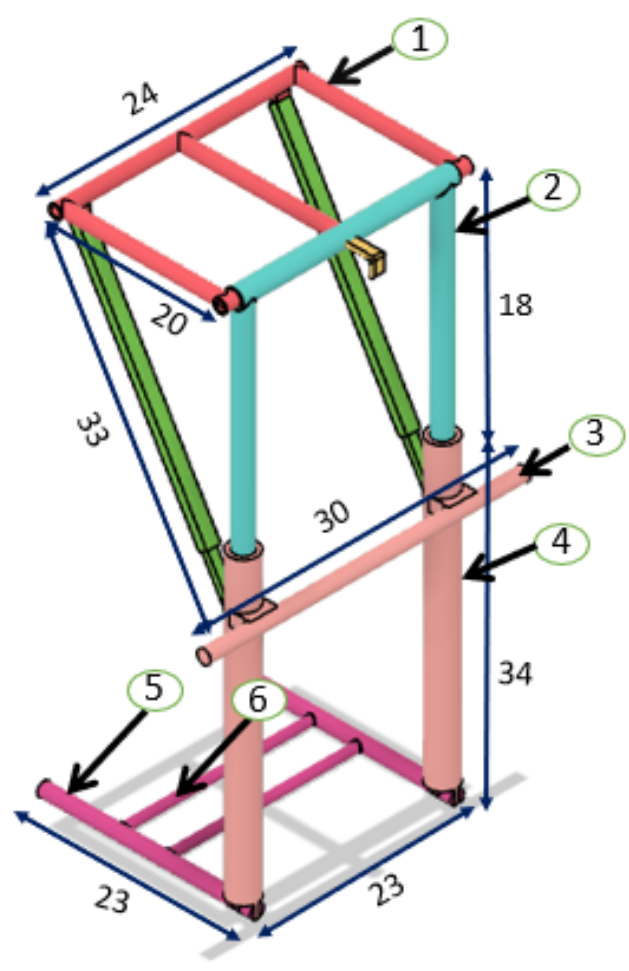

Figure 3 Tube frame (all dimensions in $\mathrm{cm}$ ).

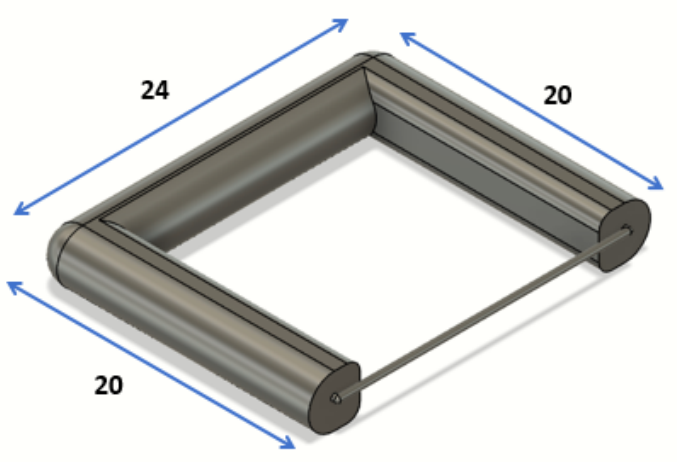

Figure 4 Handgrip for the seat (all dimensions in $\mathrm{cm}$ ).

The components shown in Figure 3 are joined by welding, hinge lock mechanism, and bolt joints with the diameter of $7.5 \mathrm{~mm}$ and $10 \mathrm{~mm}$. The bolt with the diameter of $7.5 \mathrm{~mm}$ is used to assemble component 4 and 5 while component 5 and 6 are welded. Meanwhile, the bolt with the diameter of $10 \mathrm{~mm}$ is used to fix component 2 into component 4 since they have two different diameters in one buffer support. These two different diameters are made to adjust the height of the child-seat by the user. The mechanism of this component is the same as the mechanism of a saddle of a bicycle. Component 1 is attached through component 2 to make it easy to fold. Component 3 is welded with component 4 to prop the foot of the child.
To provide a comfortable and safety feeling of the child, the seat is equipped with a handgrip (see Figure 4) and a seat belt with a baby sling model. Both of this safety equipment are attached to the backrest of the seat. The handgrip is designed with a small solid cylindrical with a diameter of $0.5 \mathrm{~mm}$ and covered with cylindrical foam with a diameter of $4 \mathrm{~cm}$ around it. It is made as a handgrip for the child to hold. The sling baby model is chosen to be the seat belt design because it gives full protection to the child's body. Moreover, the design is purposely made to be able to raise in parallel position as the backrest if it does not want to be used.

\subsection{Seat installation}

The proposed child-seat design is installed in the front deck of the motorcycle. Figure 5 illustrates the position. The red zoom mark in Figure 1 is attached to the hook which is placed in front of the motorcycle by bolts. It is made to store the seat when it is folded. At first, the user can adjust the height of the chair by modifying the two buffers' position and then lock it with the bolt. After that, the user brings up the plate with the slider part to the saddle of the motorcycle. Figure 5 shows the condition of the child-seat when it is installed and folded in a scooter motorcycle.

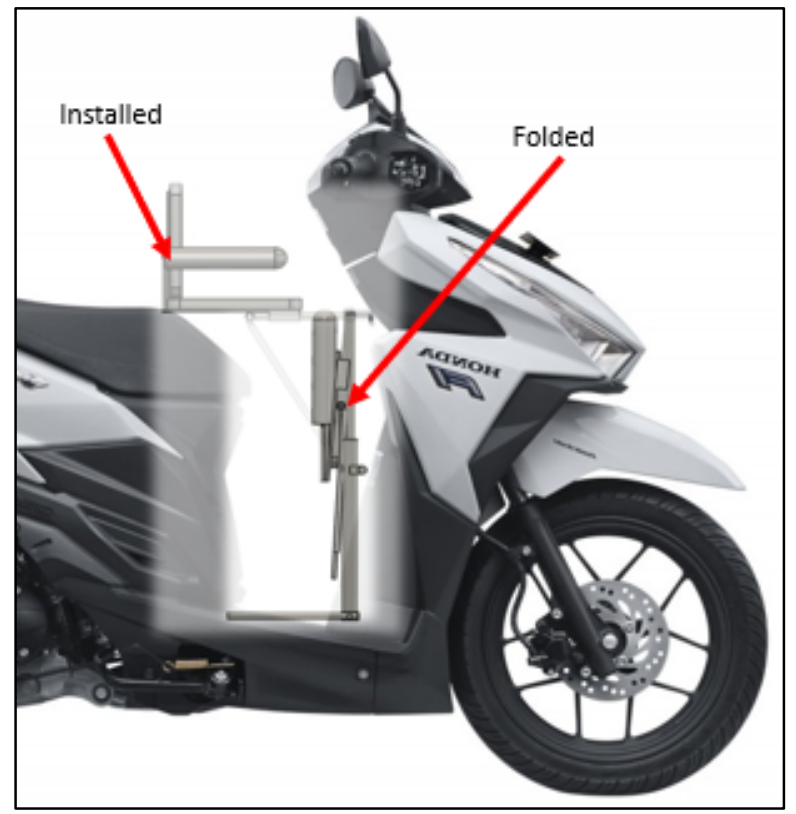

Figure 5 The child-seat position when it is installed and folded in Honda Vario scooter motorcycle. 


\subsection{Strength analysis procedure}

There are three analyses conducted to find the safety factor of each component. However, the detailed calculation in this paper is only focused on the tube component, which is component $1,2,4$, and 5 . Some equations that are used to conduct the theoretical analysis are in the following.

$$
\begin{aligned}
& I=\frac{\pi}{64}\left(d o^{4}-d i^{4}\right) \\
& \sigma=\frac{M c}{I} \text { (bending) or } \sigma=\frac{F}{A} \text { (transverse load) } \\
& \tau=\frac{V Q}{I t} \\
& \sigma_{1,2}=\frac{\sigma}{2} \pm \sqrt{\left(\frac{\sigma}{2}\right)^{2}+\tau^{2}} \\
& n=\frac{S_{y}}{\sigma_{1}-\sigma_{2}}(\text { MSS Theory) } \\
& \left.\sigma_{\text {rev }}=\frac{\sigma_{a}}{1-\frac{\sigma_{m}}{S_{u t}}} \text { (Modified Goodman }\right)
\end{aligned}
$$

Where,

$$
\begin{array}{ll}
I & : \text { second moment of area }\left(\mathrm{m}^{4}\right) \\
d_{o} & : \text { outer diameter }(\mathrm{m}) \\
d_{i} & : \text { inner diameter }(\mathrm{m}) \\
\sigma & : \text { normal stress }(\mathrm{Pa}) \\
M & : \text { bending moment }(\mathrm{Nm}) \\
C & : \text { maximum distance from neutral axis }(\mathrm{m}) \\
F & : \text { load }(\mathrm{N}) \\
A & : \text { area }\left(\mathrm{m}^{2}\right) \\
\tau & : \text { shear stress }(\mathrm{Pa}) \\
V & : \text { shear force }(\mathrm{N}) \\
Q & : \text { first moment of area }\left(\mathrm{m}^{3}\right) \\
t & : \text { width or thickness of the section }(\mathrm{m}) \\
\sigma_{1,2} & : \text { principal stress }(\mathrm{Pa}) \\
n & : \text { factor of safety } \\
S_{y} & : \text { yield strength }(\mathrm{Pa})
\end{array}
$$

By using Equation (1), Table 2 shows the area and moment inertia of the hollow tubes of component 1,2, 4 , and 5 . These are used to calculate the stress value.

Table 2 Area and moment inertia values

\begin{tabular}{ccc}
\hline No & $\begin{array}{c}\text { Area, } \mathbf{A} \\
\left(\mathbf{m}^{\mathbf{2}}\right)\end{array}$ & $\begin{array}{c}\text { Moment of Inertia } \\
\left(\mathbf{m}^{\mathbf{4}}\right)\end{array}$ \\
\hline 1 & $9.80 \times 10^{-5}$ & $1.99 \times 10^{-9}$ \\
2 & $1.37 \times 10^{-4}$ & $5.37 \times 10^{-9}$ \\
4 & $3.93 \times 10^{-4}$ & $3.19 \times 10^{-8}$ \\
5 & $9.80 \times 10^{-5}$ & $1.99 \times 10^{-9}$ \\
\hline
\end{tabular}

\section{Results and Discussion}

\subsection{Static analysis}

Static analysis is carried out to evaluate the frame's strength when the motorcycle stops. In this condition, the seat only receives the weight of the child which is $490.5 \mathrm{~N}$ (assumption of $50 \mathrm{~kg}$ mass). Figure 6 shows the free body diagram of the whole frame of the child-seat. The reaction force for each component is calculated by an equilibrium equation, creating the total force or moment equal to zero.

Based on the calculation result, it was found that component 1 (see Figure 3) was the most critical part indicated by the smallest safety factor among the two other components. This will be discussed in detail as follow.

Figure 7 shows the free body diagram of component 1 under the static condition. The distribution load was coming from the slider part on the plate component due to the child weight. From the calculation and analysis of the shear force and bending moment diagrams, the maximum shear force and bending moment for component 1 were obtained as described in the following.

$$
\begin{aligned}
& V_{\text {max }}=143.06 \mathrm{~N} \\
& M_{\text {max }}=28.61 \mathrm{Nm}
\end{aligned}
$$




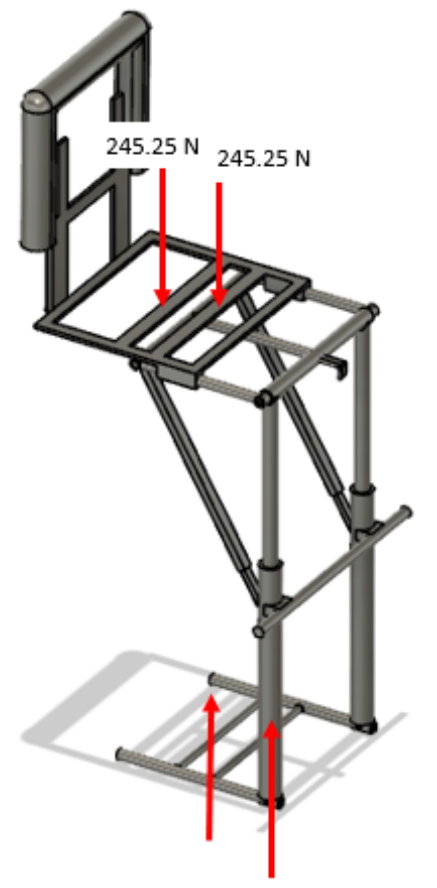

Figure 6 Free Body Diagram of the whole frame in static condition (two red arrows in the top are the applied force, and two red arrows in the bottom are the reaction force).

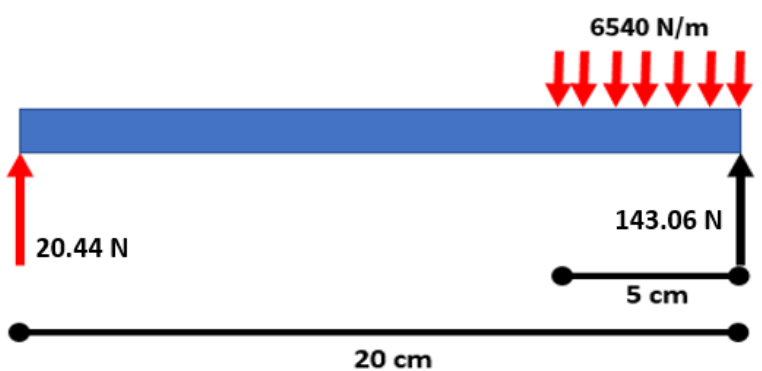

Figure 7 Free Body Diagram of component 1 under static condition.

Then, using Equations (2) and (3), the normal and shear stress are obtained as shown in the following. Furthermore, the principal stress is also calculated by the following Equation (4).

$$
\begin{aligned}
& \sigma=\frac{M c}{I}=\frac{(28.1625)(0.0075)}{1.99 \times 10^{-9}}=106.14 M P a \\
& \tau=\frac{V Q}{I t}=\frac{\frac{4}{3} V\left(R_{o}^{3}-R_{i}^{3}\right)}{\pi\left(R_{o}^{4}-R_{i}^{4}\right)\left(R_{o}-R_{i}\right)} \\
& \tau=\frac{5.66 \times 10^{-5}}{1.994 \times 10^{-11}}=2.84 M P a \\
& \sigma_{1}=106.14 M P a \\
& \sigma_{2}=0 M P a
\end{aligned}
$$

In the end, the safety factor is calculated by applying Equation (5). Table 3 shows the factor of safety for components 1, 2, 4, and 5 under static loading. Component 1 was found to be the most critical components, although its safety factor is bigger than 1, which is 3.67 . This means the seat design is in the safety zone.

Table 3 Safety factor of components in static condition

\begin{tabular}{cc}
\hline No & Safety Factor, $\mathbf{n}$ \\
\hline 1 & 3.67 \\
2 and 4 & 375.90 \\
5 & 6.29 \\
\hline
\end{tabular}

\subsection{Dynamics analysis}

As the motorcycle is moving while the child is sitting, an additional moment due to acceleration or deceleration is thus considered. The moment is generated by the force acting on the backrest of the seat. The force was calculated by using Newton's second law. The motorcycle's speed was assumed varied from 40 to $60 \mathrm{~km}$ per hour for 5 to 10 seconds. According to this condition, the acceleration of a motorcycle is generated. Then, the inertial force and the moment are obtained, which are $55.6 \mathrm{~N}$ and $5.56 \mathrm{Nm}$, respectively. The Free Body Diagram of this analysis can be seen in Figure 8. Compared with Figure 6, in Figure 8, there was an additional inertial force that acts on the backrest of the child-seat.

Based on the calculation result, the critical part due to the dynamic loading was found to be component 5 (see Figure 3). The detailed explanation about this component is as follow. Figure 9 shows the Free Body Diagram of component 5 in a dynamic condition. Here, the objective of this analysis is the same as the static analysis, as well as the calculation and the equation that are used. Based on shear force and bending moment diagrams analyses, the maximum shear force and moment for component 5 under the dynamic loading are obtained, as shown below.

$$
\begin{aligned}
& V_{\text {max }}=163.50 \mathrm{~N} \\
& M_{\text {max }}=64.83 \mathrm{Nm}
\end{aligned}
$$




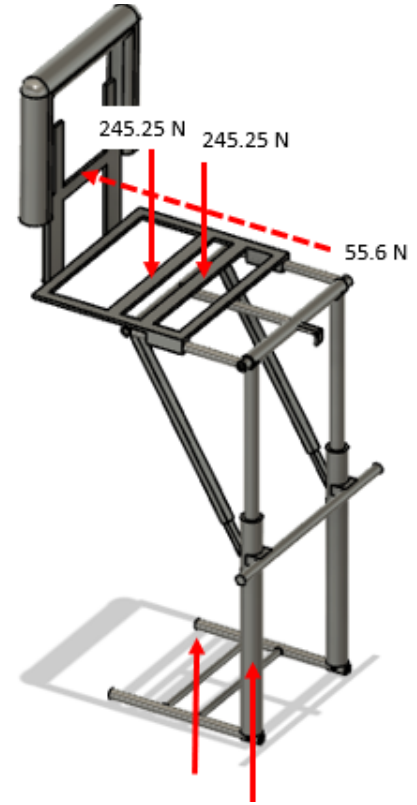

Figure 8 Free Body Diagram of the seat in dynamic condition (two red arrows in the top are the applied force, two red arrows in the bottom are the reaction force, and the dashed arrow is the inertial force).

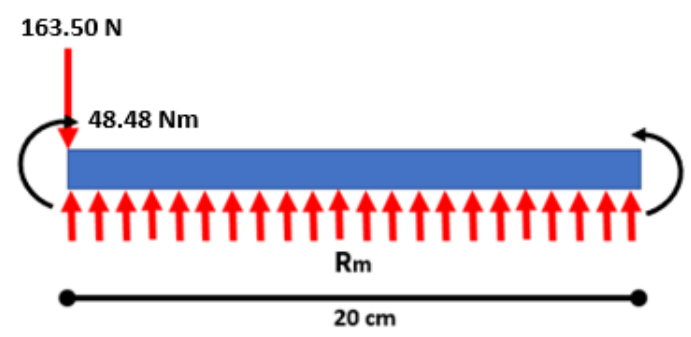

Figure 9 Free Body Diagram of component 5 in the dynamic condition

Then, by using Equations (2), (3), and (4) the normal, shear, and principal stresses are also obtained as follows.

$$
\begin{aligned}
& \sigma=\frac{M c}{I}=\frac{(64.8285)(0.0075)}{1.99 \times 10^{-9}}=244.33 \mathrm{MPa} \\
& \tau=\frac{V Q}{I t}=\frac{\frac{4}{3} V\left(R_{o}^{3}-R_{i}^{3}\right)}{\pi\left(R_{o}^{4}-R_{i}^{4}\right)\left(R_{o}-R_{i}\right)} \\
& \tau=\frac{6.47 \times 10^{-5}}{1.994 \times 10^{-11}}=3.24 \mathrm{MPa} \\
& \sigma_{1}=244.37 \mathrm{MPa} \\
& \sigma_{2}=-0.04 \mathrm{MPa}
\end{aligned}
$$

By Equations (4) and (5), the factor of safety of component 5 is obtained as 1.6. Table 4 gives the factor of safety for components $1,2,4$, and 5 .
Table 4 Safety factor of components in dynamic condition

\begin{tabular}{cc}
\hline No & Safety Factor, $\mathbf{n}$ \\
\hline 1 & 2.13 \\
2 and 4 & 1.81 \\
5 & 1.60 \\
\hline
\end{tabular}

\subsection{Life prediction analysis}

The life prediction calculation of each component is analyzed based on the maximum and minimum bending moment due to static and dynamic loading. It means the maximum bending moment is created when the inertial force on the backrest appears; meanwhile, the minimum bending moment is created when the inertial force on the backrest is not considered. However, because this condition is related to the dynamic condition with component 5 as the critical part, the detail calculation is explained in the following. To obtain the life prediction, the endurance strength needs to be determined with the Marin factors consideration. Then, the mid-range and alternating stresses are calculated based on the maximum and minimum stresses.

$$
\begin{aligned}
& \sigma_{\max }=\frac{M c}{I}=\frac{(64.8285)(0.0075)}{1.99 \times 10^{-9}}=244.33 \mathrm{MPa} \\
& \sigma_{\min }=\frac{M c}{I}=\frac{(16.35)(0.0075)}{1.99 \times 10^{-9}}=61.62 \mathrm{MPa} \\
& \sigma_{m}=\frac{\sigma_{\max }+\sigma_{\min }}{2} \\
& \sigma_{m}=\frac{244.33+61.62}{2}=152.98 \mathrm{MPa} \\
& \sigma_{a}=\frac{\sigma_{\max }-\sigma_{\min }}{2} \\
& \sigma_{a}=\frac{244.33-61.62}{2}=91.36 \mathrm{MPa}
\end{aligned}
$$

After obtaining the mid-range and alternating stress, the reversed stress is calculated based on the Modified Goodman fatigue criteria following Equation (6).

$$
\sigma_{\text {rev }}=\frac{\sigma_{a}}{1-\frac{\sigma_{m}}{s_{u t}}}=\frac{91.36}{0.68}=135.34 \mathrm{MPa}
$$

Based on the reversed stress value, it is confirmed that the value is less than the endurance strength. Therefore, an infinite life prediction for component 5 is expected. The life prediction result for components 1, 2, 4, and 5 is shown in Table 5. 
Table 5 Life prediction for component 1, 2, 4, and 5

\begin{tabular}{cccc}
\hline No & $\begin{array}{c}\text { Endurance } \\
\text { Strength } \\
\text { (MPa) }\end{array}$ & $\begin{array}{c}\text { Reversed } \\
\text { Stress } \\
\text { (MPa) }\end{array}$ & Life Prediction \\
\hline 1 & 215.01 & 55.27 & Infinite life \\
2 and 4 & 209.37 & 49.54 & Infinite life \\
5 & 215.01 & 135.34 & Infinite life \\
\hline
\end{tabular}

As the future works, the proposed child seat design needs to be further evaluated. Study and investigation about, e.g., its fabrication process [16], stress analysis using numerical simulation to predict its failure condition [17], as well as the vibration mode characteristics to make sure of its comfortableness [18], will be conducted.

\section{Conclusion}

A primary design and strength analysis of foldable child seat for scooter motorcycle under static and dynamic loading is reported in this paper. The proposed child seat design is equipped with a seat belt with a baby sling model, handgrip, and footrest. Moreover, the child seat can be folded and adjusted to fit the user condition, especially when the seat is not used. From the strength analyses, it is obtained that the critical part due to static loading is component 1 (hollow tube with attached slider); meanwhile, the critical part due to dynamic (fatigue) loading is in component 5 (hollow tube in the bottom part). It was indicated by the lowest factor of safety obtained by static and dynamic analysis which are 3.67 and 1.6, respectively. As the safety factor is still more than one, the component is considered strong enough to hold the whole weight (assumption of $50 \mathrm{~kg}$ of child weight). The proposed child-seat design is expected to become a reference for an innovative design product in transportation safety equipment.

\section{Acknowledgement}

This work is supported and funded by Faculty of Engineering and Technology (FET) and Center for Research and Community Service (CRCS), Sampoerna University under internal research grant program.

\section{References}

[1] P. Stepan, et al., "Evaluation of Motorcycle Energy Consumption in Urban Traffic," International Journal of Sustainable Transportation Technology, vol. 2, no. 1, pp. 2731, April, 2019.
[2] R. Everison, and M. Leeds, "Road Traffic Injuries in Children: findings from WA's Childhood Injury Surveillance System," in Proceedings of ACRS 2009 National Conference, November, 2009.

[3] K. Kanawipawut, J. Carmai, and S. Koetniyom, "Development of motorcycle child seats to mitigate injury during a motorcycle crash," in Proceedings of the 9th TSME International Conference on Mechanical Engineering, May, 2019

[4] A. Jusuf, I. P. Nurprasetio, and A. Prihutama, "Macro data analysis of traffic accidents in Indonesia," Journal of Engineering and Technological Sciences, vol. 49, no. 1, pp. 132-143, 2017.

[5] S. Sambasivam, et al., "Conceptual Framework for the Design of a Child Motorcycle Safety Seat," Asian Journal of Applied Sciences, vol. 4, no. 3, 2016.

[6] Fimela. 2018. Bahaya Penggunaan Kursi Rotan Untuk Anak di Motor, Moms Wajib Baca [Online]. Available: https://www.fimela.com/lifestyle-

relationship/read/3777003/bahaya-penggunaan-kursi-rotanuntuk-anak-di-motor-moms-wajib-baca\#. [Accessed: 26Apr-2020].

[7] World Health Organization. 2008. World Report on Child Injury Prevention.

[8] C. M. Murrin, G. E. Kelly, R. E. Tremblay, and C. C. Kelleher, "Body mass index and height over three generations: evidence from the Lifeways cross-generational cohort study," BMC public health, vol. 12, no. 81, 2012.

[9] Indonesia Law No. 22 of 2009 concerning Traffic and Road Transport.

[10] H. Alfriandi. 2019. Perubahan Honda Vario Dari Masa ke Masa [Online]. Available: https://www.oto.com/artikelfeature-motor/perubahan-honda-vario-dari-masa-ke-masa. [Accessed: 06-May-2020].

[11] Edmonton Structural Steel Fabrication. 2018. Advantages and Disadvantages of Structural Steel Structures [Online]. Available: $\quad \mathrm{http}: / /$ northern-weldarc.com/advantagesdisadvantages-structural-steel-structures/. [Accessed: 06May-2020].

[12] H. Aksel, and Ö. Eren, "A Discussion on the Advantages of Steel Structures in the Context of Sustainable Construction," International Journal of Contemporary Architecture The NEW ARCH, vol. 2, no. 3, 2015.

[13] AZoM. 2012. AISI 1020 Low Carbon/Low Tensile Steel [Online]. https://www.azom.com/article.aspx?ArticleID=6114\# [Accessed: 06-May-2020].

[14] R. G. Budynas, J. K. Nisbett, and J. E. Shigley. Shigleys Mechanical Engineering Design. New York, NY: McGrawHill Education, 2020.

[15] Climates to Travel. Climate - Indonesia [Online]. Available: https://www.climatestotravel.com/climate/indonesia. [Accessed: 06-May-2020].

[16] K. Saptaji, S. N. Afiqah, and R. D. Ramdan, "A Review on Measurement Methods for Machining Induced Residual Stress," Indonesian Journal of Computing, Engineering and Design (IJoCED), vol. 1, no. 2, pp. 106-120, 2019.

[17] I. P. Nurprasetio, B. A. Budiman, and F. Triawan, "Failure investigation of plastic shredding machine's flange coupling based on mechanical analysis," Indonesian Journal of Science and Technology, vol. 2, no. 2, pp. 124-133, 2017.

[18] M. Ji, K. Inaba, and F. Triawan, "Vibration characteristics of cylindrical shells filled with fluid based on first-order shell theory," Journal of Fluids and Structures, vol. 85, pp. 275-291, 2019. 